\title{
JUVENTUDES CONTEMPORÂNEAS E OS DESAFIOS DA EDUCAÇÃO, TRABALHO E CULTURA
}

\author{
CONTEMPORARY YOUTH AND THE CHALLENGES OF EDUCATION, WORK \\ AND CULTURE
}

\section{LA JUVENTUD CONTEMPORÁNEA Y LOS RETOS DE LA EDUCACIÓN, EL TRABAJO Y LA CULTURA}

\author{
Marcos Elias Emerim ${ }^{1}$ \\ https://orcid.org/0000-0002-0040-887X \\ Janaína Scopel Faé \\ https://orcid.org/0000-0002-1900-3880 \\ Josimar de Aparecido Vieira ${ }^{3}$ \\ http://orcid.org/0000-0003-3156-8590
}

\begin{abstract}
Resumo
A preocupação deste ensaio é com as juventudes contemporâneas. Nele são analisadas as inserções das juventudes contemporâneas nas esferas da cultura, da escola e do trabalho e tem por finalidade compreender os desafios postos para Educação Profissional e Tecnológica na atualidade. Foi produzido a partir de estudos realizados no componente curricular eletivo Juventude, Trabalho e Escola, oferecido no curso de Mestrado Profissional em Educação Profissional e Tecnológica que pertence ao Programa de Pós-Graduação em Educação Profissional e Tecnológica (ProfEPT) do IFRS. Desenvolvido numa perspectiva qualitativa, foi elaborado por meio de pesquisa bibliográfica, constituída de livros, artigos de periódicos e com material disponibilizado na Internet, seguindo os tipos de pesquisa descritiva e exploratória. Na sua organização foram definidas as seguintes categorias de análise: constituição do sujeito jovem e as culturas juvenis na contemporaneidade; mundo do trabalho e os espaços das juventudes e escola e formação profissional crítica dos jovens. Os resultados apontam o papel da educação para o presente e o futuro das juventudes, em que as instituições de ensino se apresentam como

\footnotetext{
${ }^{1}$ Mestrando em Educação Profissional e Tecnológica (ProfEPT - IFRS). Professor de Ensino Fundamental I da Prefeitura Municipal de Sapucaia do Sul. E-mail: marcoseemerim@gmail.com

${ }^{2}$ Mestranda em Educação Profissional e Tecnológica (ProfEPT - IFRS). Atua como professora de Educação Física no Ensino Fundamental da rede municipal de ensino de Ipê - RS. E-mail: janafae@yahoo.com.br 3 Doutor em Educação pela Pontifícia Universidade Católica do Rio Grande do Sul - PUCRS. Professor de Ensino Básico, Técnico e Tecnológico do Instituto Federal de Educação, Ciência e Tecnologia do Rio Grande do Sul (IFRS) - Campus Sertão e professor permanente do Programa de Pós-Graduação em Educação Profissional e Tecnológica (ProfEPT). E-mail: josimar.vieira@sertao.ifrs.edu.br
}

\section{Como referenciar este artigo:}

EMERIM, M.; FAÉ, J. S.; VIEIRA, J. A. juventudes contemporâneas e os desafios da educação, trabalho e cultura. Revista Pedagógica, v. 23, p. 1-18, 2021. 
oportunidades de crítica, de negociação e produção cultural e de reconhecimento das identidades culturais. Um projeto de vida não pode se limitar às escolhas profissionais, porém, a inserção no mundo do trabalho é parte importante da vida dos jovens. É importante escutar os jovens e ajudálos a enfrentar os obstáculos cotidianos para potencializar seus projetos de futuro, ajudando-os a enfrentar o poder de homogeneização que insiste em reduzi-los a um período de tempo transitório da vida.

Palavras-chave: Juventudes. Mundo do trabalho. Educação Profissional e Tecnológica. Culturas juvenis.

\section{Resumen}

La preocupación de este ensayo es la juventud contemporánea. Analiza las inserciones de la juventud contemporánea en los ámbitos de la cultura, la escuela y el trabajo para comprender los retos que se plantean a la Formación Profesional y Tecnológica en la actualidad. Se produjo a partir de los estudios realizados en el componente curricular electivo Juventud, Trabajo y Escuela, ofrecido en el curso de Maestría Profesional en Educación Profesional y Tecnológica que pertenece al Programa de Postgrado en Educación Profesional y Tecnológica (ProfEPT) del IFRS. Desarrollado en una perspectiva cualitativa, fue elaborado a través de una investigación bibliográfica, compuesta por libros, artículos de revistas y material disponible en Internet, siguiendo los tipos de investigación descriptiva y exploratoria. En su organización se definieron las siguientes categorías de análisis: constitución del sujeto joven y culturas juveniles en la contemporaneidad; mundo del trabajo y espacios juveniles; y escuela y formación profesional crítica de los jóvenes. Los resultados apuntan al papel de la educación para el presente y el futuro de los jóvenes, en el que las instituciones educativas se presentan como oportunidades para la crítica, la negociación y la producción cultural, y el reconocimiento de las identidades culturales. Un proyecto de vida no puede limitarse a las opciones profesionales, sino que la inserción en el mundo laboral es una parte importante de la vida de los jóvenes. Es importante escuchar a los jóvenes y ayudarles a afrontar los obstáculos cotidianos para potenciar sus proyectos de futuro, ayudándoles a enfrentarse al poder de la homogeneización que se empeña en reducirlos a un periodo transitorio de la vida.

Palabras clave: Juventud. El mundo del trabajo. Educación profesional y tecnológica. Las culturas juveniles.

\section{Abstract}

This essay is concerned with contemporary youth. It analyzes the insertions of contemporary youth in the spheres of culture, school and work with the purpose of understanding the challenges posed to Vocational and Technological Education today. It was produced from studies carried out in the elective curricular component Youth, Work, and School, offered in the Professional Master's Degree course in Professional and Technological Education that belongs to the Post-Graduation Program in Professional and Technological Education (ProfEPT) of IFRS. Developed in a qualitative perspective, it was elaborated by means of bibliographic research, consisting of books, journal articles, and with material available on the Internet, following the types of descriptive and exploratory research. In its organization the following categories of analysis were defined: the constitution of the young subject and the youth cultures in contemporaneity; the world of work and the spaces for youth; and school and the critical professional formation of young people. The results point to the role of education for the present and the future of young people, in which the educational institutions present themselves as opportunities for criticism, for negotiation and cultural production, and for the recognition of cultural identities. A life project cannot be limited to professional choices, but the insertion in the 
Revista do Programa de Pós-Graduação em Educação da Unochapecó

ISSN 1984-1566 (on-line) ISSN 1415-8175 (impressa)

world of work is an important part of the lives of young people. It is important to listen to young people and help them face the daily obstacles to enhance their future projects, helping them to face the power of homogenization that insists on reducing them to a transitory period of life.

Keywords: Youth. World of Work. Professional and Technological Education. Youth cultures.

\section{INTRODUÇÃO}

Este ensaio foi produzido a partir de estudos realizados no componente curricular eletivo Juventude, Trabalho e Escola, oferecido no segundo semestre do ano de 2020, pelo curso de Mestrado Profissional em Educação Profissional e Tecnológica que pertence ao Programa de Pós-Graduação em Educação Profissional e Tecnológica (ProfEPT) do Instituto Federal de Educação, Ciência e Tecnologia do Rio Grande do Sul (IFRS). A temática "juventudes" ganha relevância neste estudo na medida em que é observado, nos diversos contextos sociais, que juventude não é uma só, mas é plural, por isso, “juventudes”! Como destaca Abramovay, Andrade e Esteves (2007, p. 22), “[...] vem se tornando cada vez mais corriqueiro o emprego do termo juventudes, no plural, no sentido não de se dar conta de todas as especificidades, mas, justamente, apontar a enorme gama de possibilidades presente nessa categoria".

As juventudes podem ser retratadas e conceituadas sob vários pontos de partida, vinculados não só à uma dimensão de fase do ciclo da vida, mas à bagagem social, cultural e econômica. As percepções que temos a respeito das juventudes são muitas. Percebemos os jovens como sujeitos de passagem, ou uma ideia romantizada, de liberdade e curtição. Por outro lado, enxergamos uma fase difícil, de crise, de negatividade. Dessa forma, torna-se necessário questionar essas imagens e, por isso, propomos neste ensaio, adotar o jovem como sujeito social e modelo cultural, como sugerem, respectivamente, Dayrell (2003) e Peralva (1997).

Assim, cada juventude tem seu tempo e abarca sujeitos distintos, mas que se unem por interesses e expectativas em comum. Entre as representações sociais do ser jovem na sociedade contemporânea, possivelmente, a ampliação do tempo destinado à formação, o mercado cultural juvenil e o adiamento da inserção no mundo do trabalho são as que permeiam com maior frequência os discursos sobre o tema. 
Revista do Programa de Pós-Graduação em Educação da Unochapecó

ISSN 1984-1566 (on-line) ISSN 1415-8175 (impressa)

Diante de tal cenário, neste estudo são analisadas as inserções das juventudes contemporâneas nas esferas da cultura, da escola e do trabalho com a finalidade de compreender os desafios postos para Educação Profissional e Tecnológica (EPT) na atualidade.

Longe de propor verdades absolutas ou proposições definitivas, este trabalho é um esforço de reflexão que tem o intuito de contribuir para o debate sobre o tema em questão alcunhado de juventudes. Na sua organização consta inicialmente o percurso metodológico e na sequência são discorridas três seções: a primeira analisa a constituição do jovem e suas culturas; em seguida são analisados os cenários e os desafios que se apresentam para os jovens diante da inserção no mundo do trabalho e na terceira parte encontra-se uma problematização sobre a relação que se estabelece entre a escola e os jovens. Por fim, é apresentada uma síntese do estudo realizado nas considerações finais.

\section{PERCURSO METODOLÓGICO}

Este trabalho teve o propósito de analisar as inserções das juventudes contemporâneas nas esferas da cultura, da escola e do trabalho com a finalidade de compreender os desafios postos para EPT na atualidade. Para aproximarmos deste propósito, buscamos em Creswell (2010) e Marconi e Lakatos (2010) referências quanto ao tipo de pesquisa e definimos a abordagem qualitativa descritiva, com pesquisa bibliográfica para a produção deste estudo. Conforme Creswell (2010), a pesquisa qualitativa faz uso de estruturas teóricas e de interpretação que abordam os significados atribuídos pelos sujeitos a um problema social ou humano, incluindo a reflexão do pesquisador, a descrição e a interpretação do problema investigado.

Para a revisão da temática estudada e apresentação dos resultados, optamos pela pesquisa bibliográfica dos temas: culturas juvenis, juventude, trabalho e escola, em que foram envolvidos os seguintes autores/pesquisadores: Dayrell (2003), Peralva (1997), Freitas (2005), Bourdieu (1983), Martins e Carrano (2011), Enne (2010), Gramsci (1977, 1985), Furlani e Bonfim (2010), Bauman (1997), Antunes (2018), Leão, Dayrell e Reis (2011), Oliveira, Silva e Rodrigues (2006), Frigotto (1995, 2020), Saviani (1989), Moreira e Candau (2008), Vieira e Vieira (2016), entre outros. A escolha desses autores se deve ao fato de 
que fazem parte das referências utilizadas nos estudos realizados no componente curricular eletivo conforme consta na introdução deste trabalho.

A pesquisa bibliográfica, como sugerem Marconi e Lakatos (2010), tem a finalidade de colocar o pesquisador em contato direto com tudo o que foi escrito, analisado e estudado sobre determinado assunto. No entanto, destacam que pesquisas com esta técnica não se tratam de mera repetição de ideias, e sim, da análise “[...] de um tema sob novo enfoque ou abordagem" (MARCONI; LAKATOS, 2010, p. 183). Por se tratar de uma investigação que utiliza a pesquisa bibliográfica, está dispensado de parecer do Comitê de Ética em Pesquisa (CEP), conforme Resolução 510/2016.

No processo de revisão bibliográfica, foram definidas as categorias de análise, seguindo orientações de Minayo (2004) que aponta diferentes tipos de análise de conteúdo, ou seja, de expressão, das relações, de avaliação, de enunciação e categorial temática. Neste estudo foi dado destaque ao último tipo que se propõe a "[...] descobrir os núcleos de sentido que compõem uma comunicação cuja presença ou frequência signifiquem alguma coisa para o objetivo analítico visado" (p. 210), utilizando-a de forma mais interpretativa. Diante desta contribuição de Minayo (2004), foram definidas as seguintes categorias: juventudes na sociedade contemporânea; mundo do trabalho e os espaços das juventudes; e escola e formação profissional crítica dos jovens.

\section{JUVENTUDES NA SOCIEDADE CONTEMPORÂNEA: A CONSTITUIÇÃO DO SUJEITO JOVEM E AS CULTURAS JUVENIS}

Para o desenvolvimento deste ensaio acadêmico, utilizamos o termo juventudes. Esta escolha se deve aos escritos de Freitas (2005), em que apontam que há uma multiplicidade de perspectivas a partir das quais devem ser entendidos e inseridos os jovens da sociedade contemporânea: social, cultural, política, econômica e outras. Há assim, uma grande diversidade de universos vivenciais, perfis e características individuais e coletivas, que determinam a existência de distintas “juventudes” no tempo histórico atual.

O entendimento sobre o que vem a ser os sujeitos e grupos “jovens”, por sua vez, passa por aquilo que Dayrell (2003) defende: 
Se há um caráter universal dado pelas transformações do indivíduo numa determinada faixa etária, nas quais completa o seu desenvolvimento físico e enfrenta mudanças psicológicas, é muito variada a forma como cada sociedade, em um tempo histórico determinado, e, no seu interior, cada grupo social vão lidar com esse momento e representá-lo. Essa diversidade se concretiza com base nas condições sociais (classes sociais), culturais (etnias, identidades religiosas, valores) e de gênero, e também das regiões geográficas, dentre outros aspectos (DAYRELL, 2003, p. 40).

Nesta direção, mais do que uma delimitação biológica ou "legal” (algo que, diga-se de passagem, não existe na legislação brasileira), compreende-se como "jovem” uma fase específica de vida, marcada por transições e transformações que, como destacado pelo autor, são influenciadas e representadas por cada sociedade e seu tempo histórico vivido.

Outrossim, Bourdieu (1983) mostra que definir o período da juventude pela idade, é manipular socialmente estes dados. Da mesma forma como falar dos jovens como unidade social, homogênea, dotada de interesses comuns, e relacioná-los a uma idade definida biologicamente também se trata de um processo de manipulação.

As formas de inserção social e o acesso aos bens culturais e de consumo são fortes delimitadores dos grupos juvenis. O mercado desses bens, de acordo com seus interesses, procura direcionar os jovens para o consumo e os moldar. Como as condições de oferta e de acesso não são as mesmas para todos, os jovens aproximam-se daqueles que compartilham dos mesmos signos.

Para Martins e Carrano (2011), os referenciais simbólicos pelos quais os jovens se identificam funcionam como um elo entre os iguais, mas que se diferenciam de outros grupos juvenis. Mais uma vez reforçando o entendimento da utilização do termo juventudes, pensadas pelo viés da diversidade, com suas diferentes marcas identitárias.

Considerando ainda os processos constitutivos identitários das juventudes, Enne (2010) mostra como os bens de consumo são fundamentais em suas caracterizações:

Os bens adquiridos serão fundamentais no processo de significação das propostas igualitárias e nas de distinção, que se alternarão no jogo identitário de acordo com as fronteiras culturais que se estabelecem ou se busca estabelecer. Por vezes, os objetos serão marcas de singularidade e separação. Em outras, serão instrumental decisivo para construção de pertencimentos e aceitação. Adensando de forma definitiva o que já vinha fazendo desde a sua constituição, 
a cultura midiática será central no fornecimento de imagens e diretrizes para os sujeitos vivenciarem esse dramático jogo de personalizar-se sem perder, com isso, seus liames culturais (ENNE, 2010, p. 23).

Nesses espaços marcados por identidades distintas, nota-se também certa instabilidade, haja visto que a inovação tecnológica e a difusão de informação em massa atravessam as juventudes modificando seus interesses. Sendo assim, o período da juventude não é mais rígido e linear, e sim, marcado por um vai-e-vem de práticas, posicionamentos e valores que colocam os jovens em sua condição de sujeito social.

É neste contexto instável - em conjunto com os condicionantes socioeconômicos que acabam delimitando as estruturas no processo de transição para a vida adulta - que os jovens realizam suas escolhas e constituem suas trajetórias sociais.

A sociedade contemporânea, ao mesmo tempo em que proporciona oportunidades para os jovens se fazerem vistos e ouvidos, também falta em estrutura e políticas públicas efetivas. As juventudes das cidades grandes, das metrópoles, enfrentam problemas de mobilidade em suas tentativas de inserção social: o trânsito; o tempo de deslocamento; as diferenças sociais entre os bairros urbanos, e também entre os meios rural e urbano. Quem vive no interior sofre com a falta de opções de lazer, estudo, trabalho e cultura. O sonho de uma vida melhor e a resposta àquela velha pergunta "o que você quer da vida?" precisam superar essas barreiras para serem efetivados.

Uma possibilidade para auxiliar nesse enfrentamento é a articulação e a mobilização das juventudes. Movimentos sociais como os estudantis, ambientais, religiosos, LGBT, dão voz aos jovens e ampliam o campo de possibilidades, quase sempre limitados pelo território e contexto social e econômico em que se inserem. A mobilização em prol da arte e da cultura, seja pelo resgate dos costumes geracionais ou pelo moderno também costuma render bons frutos.

Enfim, sob a aparente hegemonia e inquietação das juventudes, o que temos, de fato, é uma diversidade de identidades inquietas, que se aproximam, se articulam e se mobilizam em prol de viverem a juventude em sua plenitude e de elaborar seus projetos de vida com segurança e tranquilidade.

Entrementes, há uma complexa multiplicidade de fatores a serem observados e refletidos na busca por caracterizar as juventudes na sociedade contemporânea. Ao 
Revista do Programa de Pós-Graduação em Educação da Unochapecó

ISSN 1984-1566 (on-line) ISSN 1415-8175 (impressa)

mesmo tempo que fazem parte do todo social e, como todos os sujeitos sociais, constituem-se sendo influenciadas e determinadas pelos padrões e ideologias dominantes (GRAMSCI, 1995), possuem também os seus próprios grupos e universos de vida e expressão.

De modo que, para compreender adequadamente o desenvolvimento desses sujeitos na sociedade, é fundamental analisar as questões referentes ao seu processo de inserção no mundo do trabalho e como a educação formal está ou não preparada para lidar com a diversidade juvenil e suas diferentes realidades existentes.

\section{MUNDO DO TRABALHO E OS ESPAÇOS DAS JUVENTUDES: CENÁRIOS ATUAIS E DESAFIOS}

As diferentes inserções sociais e as diversas maneiras de planejar os projetos de vida levam-nos a refletir sobre as muitas possibilidades de entender as juventudes. Assim, compreendemos o jovem como sujeito social, que se constrói a partir da sua realidade e do campo de possibilidades que essa lhe permite.

A juventude se relaciona com o lugar, o bairro, a comunidade onde vive. A rua e a comunidade em que habitamos, seja na área urbana ou rural, dizem muito a respeito de nossas vidas e também sobre o modo como nos relacionamos com os outros e com as coisas ao nosso redor. Longe de serem meros cenários onde as coisas acontecem, esses locais de morada e convivência condicionam e, ao mesmo tempo, são condicionados por práticas sociais, econômicas e histórico-culturais, constituindo-se, assim, em territórios que marcam e são marcados pela população que neles reside e convive (OBSERVATÓRIO DA JUVENTUDE, 2014)

Acompanhando este pensamento, em Martins e Carrano (2011) reconhecemos que os espaços da juventude são transformados em territórios culturalmente expressivos, onde as identidades são elaboradas. Nesses territórios delineiam-se espaços de autonomia que os jovens buscam conquistar, entre eles, o espaço da autonomia financeira por meio da inserção no mundo do trabalho.

Tais cenários - o mundo do trabalho e os espaços juvenis - estão intimamente relacionados, e na maioria das vezes, reafirmam a dificuldade vivenciada pelas 
Revista do Programa de Pós-Graduação em Educação da Unochapecó

ISSN 1984-1566 (on-line) ISSN 1415-8175 (impressa)

juventudes. Seja porque a inserção no mundo do trabalho nem sempre ocorre apenas para conquistar sua autonomia, e sim, para ajudar no sustento da família, o que não lhes permitem subsídios para ter acesso à cultura e ao lazer; seja pelas incertezas em todos os aspectos que permeiam a vida dos sujeitos na contemporaneidade.

A Lei $n^{\circ} 12.852 / 2013$, que institui o Estatuto da Juventude, expressa que o jovem tem direito à profissionalização, ao trabalho e à renda, exercido em condições de liberdade, equidade e segurança, adequadamente remunerado e com proteção social. Para efetivação desse direito, lança mão de medidas como a oferta de condições especiais de jornada de trabalho por meio de compatibilização entre horários de trabalho e estudo e oferta de níveis e modalidades de ensino em horários compatíveis com a frequência escolar e o trabalho regular (BRASIL, 2013).

No entanto, este texto não traduz a realidade da maioria dos jovens. Neste contexto, segundo Dayrell (2003), para alguns jovens, o mundo do trabalho não lhes dá a opção de escolha e o trabalho é encarado como uma obrigação necessária. E a situação se agrava quando o estudo é deixado de lado. Por outro lado, há os jovens que vivem na inércia, protelando seus projetos de vida e postergando a entrada no mundo do trabalho. Há ainda os jovens que conseguem fazer suas escolhas profissionais, mas que acabam caindo no dilema da dúvida e da incerteza, afinal é cedo para escolher. É uma decisão precoce que irá permear os projetos de vida, a fase adulta, enfim, o decorrer de sua existência (DAYRELL, 2013).

Em qualquer uma das situações, notamos a influência da situação econômica e social na constituição do sujeito social. E aqueles que precisam antecipar a entrada na vida adulta pelo trabalho precoce, acabam não vivenciando a fase de experimentação e escolhas que caracteriza as juventudes.

A trajetória de busca e inserção no mundo do trabalho pelos jovens é desigual entre as diferentes classes sociais. Aos jovens de baixa renda e escolaridade, cabe ocupar as vagas disponíveis, sem expectativa de progressão, ou aderir ao trabalho informal. Já aos que têm melhores condições, lhes são oportunizadas a moratória social, que permite que o jovem adie sua inserção no mundo do trabalho para dedicar-se aos estudos e, consequentemente, alcançar melhores carreiras profissionais. 
Revista do Programa de Pós-Graduação em Educação da Unochapecó

ISSN 1984-1566 (on-line) ISSN 1415-8175 (impressa)

Diferenças no mundo do trabalho entre os jovens também aparecem quando comparados os meios rural e urbano. O estudo de Furlani e Bomfim (2010) aponta que os jovens do meio rural tendem a começar a trabalhar mais cedo que os jovens do meio urbano, no entanto, revelam tratar-se de trabalho informal e não assalariado ou com direitos trabalhistas assegurados. Outro dado importante é que os jovens do meio rural sentem falta de oportunidades e opções de escolha de emprego, o que os leva a pensarem em sair do campo.

Gaudêncio Frigotto, em uma live realizada no Youtube por meio do canal Movimento por uma Escola Popular (MEP Sinasefe), com o tema "Juventude e trabalho no pós-pandemia", relata que um em cada quatro jovens brasileiros não trabalha e não estuda. Sinal de alerta, algo precisa mudar. O sistema precisa mudar! As juventudes precisam se unir, o sistema educacional engessado precisa rever seus conceitos, as relações de trabalho precisam ser revistas. De fato, a relação entre os jovens e o mundo do trabalho é uma pequena fatia das mazelas que acometem as juventudes (FRIGOTTO, 2020).

Vale destacar a consideração de Furlani e Bomfim (2010) de que nossa cultura valoriza o trabalho, categorizando o sujeito a partir do que ele faz, mas “[...] ao mesmo tempo em que atribui alto valor ao trabalho, por conta do capitalismo, não oferece oferta de trabalho para toda a população, sendo o desemprego ou subemprego um grave problema da atualidade" (FURLANI; BOMFIM, 2010, p. 58). Esta consideração vai ao encontro de Dayrell (2003), no sentido de que qualquer instituição, entre elas o trabalho, não exercerá plenamente sua função “[...] se não estiver acompanhada de uma rede de sustentação mais ampla, com políticas públicas que garantam espaços e tempos para que os jovens possam se colocar de fato como sujeitos e cidadãos" (DAYRELL, 2003, p. 51).

Isso é especialmente importante no cenário atual, no qual as relações de produção e empregabilidade do mundo do trabalho - destacadamente o "mercado de trabalho" - e por consequência os demais aspectos que envolvem a vida dos trabalhadores - passam por uma etapa de múltiplas incertezas e instabilidades, onde predomina a inconstância nas idealizações e desenvolvimentos de carreiras e perspectivas dos indivíduos a média/longo prazo (BAUMAN, 1997). 
Revista do Programa de Pós-Graduação em Educação da Unochapecó

ISSN 1984-1566 (on-line) ISSN 1415-8175 (impressa)

No mesmo sentido, Antunes (2018) destaca que a situação do trabalho na sociedade atual pauta-se pela precarização geral das relações e formas de trabalho (terceirização, informalidade, prestação de serviços temporários) e a fragmentação e desregulamentação que atinge as atividades profissionais nas quais atua especialmente a classe trabalhadora, ao mesmo tempo que aumentam as exigências por maior escolarização, diminuem os direitos/garantias trabalhistas e limitam-se os postos de trabalho formais - algo que impacta diretamente na ocupação profissional das novas gerações.

Diante disso, está posta a necessidade de uma educação formal que ofereça às juventudes atuais a possibilidade de uma formação e orientação profissional adequada, de forma integral e crítica - de modo que os jovens possam evoluir livremente em suas culturas e expressões de vida, com a perspectiva de se desenvolverem adequadamente no mundo do trabalho, transformando assim as suas próprias realidades e contribuindo para a transformação de toda a sociedade.

\section{ESCOLA E FORMAÇÃO CRÍTICA DOS JOVENS}

$\mathrm{Na}$ sociedade atual, a escola destaca-se como a instituição social oficialmente responsável pela formação e orientação educacional das pessoas - especialmente os sujeitos jovens. Naturalmente, são muitas as complexidades e contradições que influenciam e/ou emergem dos processos relacionados ao universo escolar: desde os múltiplos conceitos e entendimentos acerca dos limites e prerrogativas da educação formal e o seu papel na sociedade (como o que seria a "função da escola" e o que é de “responsabilidade das famílias”), até as diferentes idealizações de modelos políticos, pedagógicos, metodológicos, didáticos, filosóficos, etc.

Neste ensaio, vislumbramos a educação escolar de acordo com os princípios propostos pelas bases conceituais da EPT: que se comprometa em promover a equidade social, oferecer formação e orientação integral que dialogue com as diferentes realidades socioculturais e que garanta aos indivíduos e suas coletividades, independentemente das suas origens socioeconômicas e culturais, uma adequada preparação para a inserção profissional crítica no mundo do trabalho (BRASIL, 2007). “Tal educação requer não 
apenas formação que articule a competência científica e técnica com a inserção política e a postura ética, mas também a capacidade de produzir e aplicar os conhecimentos técnicos e científicos, através de critérios de relevância social e ética" (VIEIRA; VIEIRA, 2016, p. 84).

Como destacam Martins e Carrano (2011), é necessário compreender que:

[...] processos sociais e culturais contemporâneos produtores das denominadas culturas juvenis [...] chamam a atenção para o necessário reconhecimento desses processos pela escola. Os grupos culturais juvenis são decisivos na socialização dos jovens que frequentam a escola de Ensino Médio que, além de alunos, são, também, sujeitos de outros espaços e tempos culturais da cidade. (MARTINS; CARRANO, 2011, p. 43).

Assim, a não observância das instituições de ensino em relação às demandas e expectativas dos jovens acaba por fazer do ambiente escolar uma arena de conflitos entre as identidades culturais juvenis e a cultura tradicional escolar já estabelecida. "“[...] são negadas aos Jovens as suas diferenças culturais e a flexibilidade, estando presentes formatos pouco dinâmicos, de posturas, de recursos didáticos utilizados nas aulas e as próprias salas de aula, as quais engessam os sentidos e o encantamento pela escola" (SILVA; OVIGLI, 2020, p. 4).

A escola já não é mais o único local onde se encontram as informações e o conhecimento e, na maioria das vezes, parece desconsiderar os espaços culturais e simbólicos onde os jovens estão inseridos. Assim, assume-se uma escolarização sem sentido. Como apontam Leão, Dayrell e Reis (2011), os jovens depositam grandes expectativas na escola, mas por outro lado, revelam o limite que ela tem em corresponder às suas demandas.

Podemos perceber a relevância de um currículo que se aproxime da realidade dos jovens, articulando os conteúdos com o cotidiano. E ainda, que possibilite uma compreensão da realidade onde estão inseridos, uma visão sobre o mundo do trabalho e suas exigências, como sugerem os autores. Em relação aos projetos de vida, afirmam, de maneira geral, que os jovens centram suas formulações "em torno das expectativas de escolarização articuladas com o mundo do trabalho", o que reforça “[...] a centralidade da escola e do trabalho na constituição de uma determinada condição juvenil” (LEÃO; DAYRELL; REIS, 2011, p. 1075). 
Revista do Programa de Pós-Graduação em Educação da Unochapecó

ISSN 1984-1566 (on-line) ISSN 1415-8175 (impressa)

Constatação semelhante é feita por Oliveira, Silva e Rodrigues (2006), que ao abordarem a temática do acesso, identidade e pertencimento das culturas juvenis, identificaram a estreita relação entre educação e trabalho demonstrada pelos jovens, sendo estes, meios para garantir a autonomia e poder investir em cultura e lazer.

Urge, portanto, a necessidade de uma educação preparada para pensar a unidade entre o ensino, pesquisa e extensão e o trabalho produtivo, o trabalho enquanto princípio educativo e a perspectiva da escola politécnica (FRIGOTTO, 1985). Considerando que a instrução das pessoas ocorre de uma geração para outra por meio das relações materiais de trabalho existentes na sociedade, é preciso formar os jovens de forma que assumam o controle consciente dos processos produtivos, fazendo-se assim, produtores de si mesmos, e desenvolvendo a compreensão crítica acerca das suas posições sociais e colocação no mundo material (GRAMSCI, 1977).

Esse modelo de educação, entendida como Educação Politécnica e que encontra no Brasil a alternativa EPT e o EMIEP, postula, nas palavras de Saviani (1989):

[...] que o trabalho desenvolva, numa unidade indissolúvel, os aspectos manuais e intelectuais... [pois] todo trabalho humano envolve a concomitância do exercício dos membros, das mãos e do exercício mental, intelectual. Isso está na própria origem do entendimento da realidade humana, enquanto constituída pelo trabalho (SAVIANI, 1989, p. 15).

Assim, tendo em vista a sociedade atual e as problemáticas ora analisadas neste ensaio, a educação de inspiração politécnica torna-se uma possibilidade no horizonte. Diante da natureza institucional da Educação Básica no Brasil, em especial na sua etapa de ensino médio, é preciso oferecer aos estudantes uma prática pedagógica que não apenas os instrumentalizem e reforcem os perfis das realidades socioeconômicas e culturais nas quais estão inseridos, mas que, partindo da compreensão das mesmas, prepare-os para a busca pela transformação de suas próprias vidas e a da coletividade.

\section{CONSIDERAÇÕES FINAIS}

São nas relações de sociabilidade, sejam elas geracionais, escolares, de amizade, no trabalho ou de pertencimento, que as juventudes se constituem e constroem suas 
Revista do Programa de Pós-Graduação em Educação da Unochapecó

ISSN 1984-1566 (on-line) ISSN 1415-8175 (impressa)

identidades. Em cada um desses contextos se faz presente a heterogeneidade que vem caracterizando a categoria "juventude".

Quando compreendemos os jovens como sujeitos sociais, e não apenas como um ser em processo de transição, assumimos, como Enne (2010), a juventude como categoria-chave da modernidade. No entanto, por vezes se comete o erro de creditar nessa categoria a responsabilidade de solucionar os problemas do mundo, quando na verdade, o que eles querem e precisam, é viver o seu tempo, constituir-se de acordo com seus estilos e interesses, e claro, elaborar seus projetos de vida.

Em alguns casos - se não na maioria deles - os bens culturais e os campos de possibilidades disponíveis não permitem que muitas das expectativas saiam do papel. Analisando melhor, nem sequer há grandes expectativas. Eis que destacamos então o papel fundamental da educação para o presente e o futuro das juventudes. A escola precisa ter sentido para quem a frequenta.

Os elementos de tensão entre o jovem e a escola aparecem quando o currículo não atende as expectativas, quando não há abertura para conhecer o estudante além das quatro paredes da sala de aula, quando o silêncio impera. Soma-se também a dificuldade do jovem tentar compreender o outro lado. É provável que não tenha conhecimento de como está estruturado o sistema de ensino, de como conteúdos e currículos estão ancorados social e historicamente, e de que maneira pode ele, sujeito de deveres e direitos, contribuir na negociação em busca de uma formação com significados.

Diante dessas considerações, Moreira e Candau (2008) destacam expressões pertinentes. Primeiro, apontam as trajetórias labirínticas, que se referem às fases da vida, na qual concordamos com os autores na medida em que entendemos que essas trajetórias já não são mais lineares e nem seguem o velho roteiro: concluir os estudos, trabalhar, sair de casa, constituir moradia, casar e ter filhos, ou seja, cada juventude tem seu tempo. Depois, os autores propõem que o currículo escolar seja como um tabuleiro de xadrez: várias peças, funções, deslocamentos, mas focados em um objetivo comum - o xeque-mate.

Destarte, com este estudo percebemos ser fundamental que as instituições de ensino e todos os espaços de ensino, mais do que nunca, se apresentem como 
Revista do Programa de Pós-Graduação em Educação da Unochapecó

ISSN 1984-1566 (on-line) ISSN 1415-8175 (impressa)

oportunidades de crítica, de negociação e produção cultural, onde as identidades culturais sejam reconhecidas.

Após considerarmos as juventudes nas suas identidades, culturas e territórios escolares, é relevante uma nota sobre o mundo do trabalho. Um projeto de vida não pode se limitar às escolhas profissionais, porém, a inserção no mundo do trabalho soma um grande peso e é parte importante da vida dos jovens. Existem os prós e contras de estudar e trabalhar ao mesmo tempo, e grande parte desta parcela da população não tem escolha, tem que trabalhar para o sustento da família, ou para o sustento da sua condição de ser jovem, de acessar o que Ihes dá características, o que lhe faz pertencer ao seu grupo.

É preciso escutar os jovens e, por meio de ações concretas e políticas públicas efetivas, ajudá-los a enfrentar os obstáculos cotidianos que os impedem de potencializar seus projetos de futuro. Estar atento às suas especificidades e demandas, no intuito de livrá-los do poder de homogeneização que insiste em reduzi-los a um simples período de tempo transitório da vida.

Outros desafios e perspectivas pairam nas reflexões sobre os jovens diante do contexto atual. Por se tratar de uma análise inacabada, sugerimos outras buscas teóricas e empíricas de aspectos que problematizem as juventudes na contemporaneidade. As considerações aqui situadas são inacabadas e requerem ser aprofundadas e melhor validadas em outras investigações, buscando compreender os jovens como sujeitos sociais.

\section{REFERÊNCIAS}

ABRAMOVAY, Miriam; ANDRADE, Eliane Ribeiro; ESTEVES, Luiz Carlos Gil. Juventudes: outros olhares sobre a diversidade. Brasília: Ministério da Educação, Secretaria de Educação Continuada, Alfabetização e Diversidade; Unesco, 2007. Disponível em: http://forumeja.org.br/files/Vol\%2027_ed\%201_Juventudes.pdf. Acesso em: 15 jun. 2021.

ANTUNES, Ricardo. O privilégio da servidão: o novo proletariado de serviços na era digital. São Paulo: Boitempo, 2018.

BAUMAN, Zygmunt. Modernidade líquida. Rio de Janeiro: Jorge Zahar Editora, 1997. BOURDIEU, Pierre. Questões de sociologia. Rio de Janeiro: Marco Zero, 1983. 
Revista do Programa de Pós-Graduação em Educação da Unochapecó

ISSN 1984-1566 (on-line) ISSN 1415-8175 (impressa)

BRASIL. Lei n 12.852, de 5 de agosto de 2013. Estatuto da Juventude. Brasília: Diário Oficial da União, 2013. Disponível em: http://www.planalto.gov.br/ccivil_03/_ato20112014/2013/lei/l12852.htm. Acesso em: 01 mar. 2021.

BRASIL. Ministério da Educação. Secretaria de Educação Profissional e Tecnológica. Documento Base. 2007. Disponível em:

http://portal.mec.gov.br/setec/arquivos/pdf/documento_base.pdf. Acesso em: 29 out. 2013.

CRESWELL, John W. Projeto de pesquisa: métodos qualitativo, quantitativo e misto. 3. ed. Porto Alegre: ARTMED, 2010.

DAYRELL, Juarez Tarcísio. O jovem como sujeito social. Revista Brasileira de Educação, Belo Horizonte, n. 24, p. 40-52, 2003. Disponível em:

https://www.scielo.br/pdf/rbedu/n24/n24a04.pdf. Acesso em: 01 mar. 2021.

ENNE, Ana Lucia. Juventude como espírito do tempo, faixa etária e estilo de vida: processos constitutivos de uma categoria-chave da modernidade. Comunicação, Mídia e Consumo, São Paulo, v. 7, n. 20, p.13-35, nov. 2010. Disponível em:

http://revistacmc.espm.br/index.php/revistacmc/article/view/203. Acesso em: 02 mar. 2021.

FREITAS, Maria Virgínia (Org.). Juventude e adolescência no Brasil: referências conceituais. São Paulo: Ação Educativa, 2005.

FRIGOTTO, Gaudêncio. Trabalho como princípio educativo: por uma superação das ambiguidades. Boletim Técnico do SENAC, Rio de Janeiro, v. 11, n. 3, p. 175-182, set /dez. 1985 .

FRIGOTTO, Gaudêncio. Juventude e trabalho no pós-pandemia. Disponível em: https://www.youtube.com/watch?v=wrOlf3OEvvl. Acesso em: 02 mar. 2021.

FURLANI, Daniel Dias; BOMFIM, Zulmira Áurea Cruz. Juventude e afetividade: tecendo projetos de vida pela construção dos mapas afetivos. Psicologia \& Sociedade, v. 22, n. 1, p. 50-59, 2010. Disponível em: https://www.scielo.br/pdf/psoc/v22n1/v22n1a07.pdf. Acesso em: 01 mar. 2021.

GRAMSCI, Antonio. Os intelectuais e a organização da cultura. 9. ed. Rio de Janeiro: Civilização Brasileira, 1995.

GRAMSCI, Antonio. Quaderni del carcere. Edizione critica. Organização Gerratana. Turim: Einaudi, 1977. v. 4.

UNIVERSIDADE FEDERAL DE MINAS GERAIS (UFMG). Observatório da Juventude. Iniciando o mosaico. Belo Horizonte, 2014. Disponível em: 


\section{REVISTA}

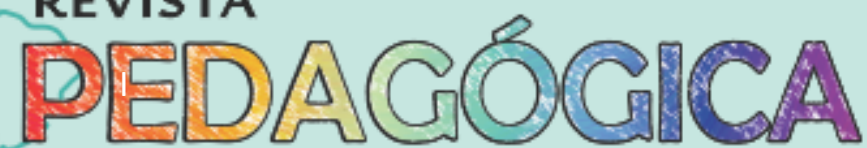

Revista do Programa de Pós-Graduação em Educação da Unochapecó

ISSN 1984-1566 (on-line) ISSN 1415-8175 (impressa)

http://observatoriodajuventude.ufmg.br/juviva-conteudo/05-02.html. Acesso em 28 nov. 2020.

LAKATOS, Eva Maria; MARCONI, Marina de Andrade. Fundamentos de metodologia científica. 7. ed. São Paulo: Atlas, 2010.

LEÃO, Geraldo; DAYRELL, Juarez Tarcísio; REIS, Juliana Batista dos. Juventude, projeto de vida e ensino médio. Educ. Soc., Campinas, v. 32, n. 117, p. 1067-1084, out./dez. 2011. Disponível em: https://www.scielo.br/scielo.php?pid=S0101-

73302011000400010\&script=sci_abstract\&tlng=pt. Acesso em: 02 mar. 2021

MARTINS, Carlos Henrique dos Santos; CARRANO, Paulo Cesar Rodrigues. A escola diante das culturas juvenis: reconhecer para dialogar. Revista Educação - UFSM, Santa Maria, v. 36, n. 1, p. 43-56, 2011. Disponível em:

https://periodicos.ufsm.br/reveducacao/article/view/2910. Acesso em: 20 nov. 2020.

MINAYO, Maria Cecília de Souza. O desafio do conhecimento: pesquisa qualitativa em saúde. 8. ed. São Paulo: Hucitec-Abrasco, 2004.

MOREIRA, Antônio Flávio; CANDAU, Vera Maria (Orgs.). Multiculturalismo: diferenças culturais e práticas pedagógicas. 2. ed. Petrópolis, RJ: Vozes, 2008.

OLIVEIRA, Júlia Ribeiro de; SILVA, Lúcia Isabel C.; RODRIGUES, Solange S. Acesso, identidade e pertencimento: relações entre juventude e cultura. Democracia Viva: Revista do Ibase Rio de Janeiro, n. 30, p. 62-65, jan./mar. 2006. Especial Juventude e Política. Disponível em: https://www.ibase.br/userimages/ibasenet_dv30_artig04.pdf. Acesso em: 02 mar. 2021.

PERALVA, Angelina. O jovem como modelo cultural. Revista Brasileira de Educação. n. 5, mai./ago., 1997; n. 6, set./dez. 1997. Disponível em:

https://anped.org.br/sites/default/files/rbe/files/rbe_05_e_06.pdf. Acesso em: 02 mar. 2021.

SAVIANI, Dermeval. Sobre a concepção de politecnia. Rio de Janeiro: FIOCRUZ-EPSJV, 1989.

SILVA, Mônica Izilda da; OVIGLE, Daniel Fernando Bovolenta. Olhares juvenis para as escolas: gaiolas ou asas? Revista Pedagógica. v. 22, 2020. Disponível em:

https://bell.unochapeco.edu.br/revistas/index.php/pedagogica/issue/view/Vol.\%2022\%2C\%2 02020. Acesso em: 02 mar. 2021.

VIEIRA, Josimar de Aparecido; VIEIRA, Marilandi Maria Mascarello. Formação integrada do ensino médio com a educação profissional: o que dizem as pesquisas. Revista Thema, Pelotas, v. 13, n. 1, p. 79-92, 2019. Disponível em:

http://periodicos.ifsul.edu.br/index.php/thema/article/view/287. Acesso em: 02 mar. 2021. 


\section{REVISTA}

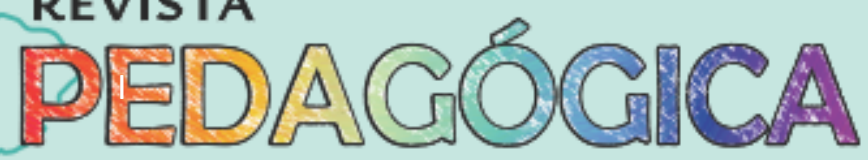

Revista do Programa de Pós-Graduação em Educação da Unochapecó ISSN 1984-1566 (on-line) ISSN 1415-8175 (impressa)

Recebido em: 02 - 03 - 2021

Aprovado em: 17 - 06 - 2021

Publicado em: 25-06- 2021 